\title{
VENEZUELA: DIFICULDADES E CONTRADIÇÕES PARA A ATUAÇÃO ANTISSISTÊMICA **
}

\author{
VENEZUELA: ADVERSITY AND CONTRADICTIONS \\ FOR ANTISYSTEMIC CONDUCT
}

\author{
Charles Pennaforte $e^{(* *)}$ \\ Centro de Estudos em Geopolítica e Relações \\ Internacionais, Rio de Janeiro (RJ), Brasil
}

Resumo: A administração Hugo Chávez (1999-2013) conseguiu importantes avanços no campo social, melhorando os indicadores sociais e econômicos da população mais pobre do país. No cenário internacional, adotou um discurso anti-imperialista e anti-EUA para marcar sua posição como uma alternativa à globalização neoliberal. Sua atuação se desenvolveu dentro do espectro antissistêmico, ao buscar promover a contestação da hegemonia norte-americana e a construção de um mundo multipolar e de uma América Latina com menor influência política de Washington.

Palavras-chave: Revolução Bolivariana; Atuação antissistêmica; Desafio aos EUA.

\begin{abstract}
The administration of the Venezuelan ex-leader Hugo Chavez has managed major advances in improving the social economic and social indicators of the poorest in the country. On the international scene has adopted an anti-imperialist and anti-US to mark its position as an alternative to neoliberal globalization. His performance is developed within the spectrum anti systemic to seek to promote the reduction of U.S. hegemony and seeks to build a multipolar world and Latin America with a less political influence in Washington.
\end{abstract}

Keywords: Bolivarian Revolution; Anti systemic Practice; Challenge to the U.S.A.

(*) O presente artigo é uma adaptação e resumo da tese de doutoramento "Movimientos Anti-Sistémicos en el Sistema-Mundo: el Caso Venezoelano", defendida em 2013 na Facultad de Ciencias Juridicas da Universidad Nacional de La Plata, sob a orientação do Professor Dr. Roberto Miranda.

(**) Doutor, Diretor-geral do Centro de Estudos em Geopolítica e Relações Internacionais (CENEGRI); Coordenador-Geral da Rede Latino-Americana de Geopolítica e Estratégia (RELAGE); Coordenador do MBA em Geopolítica e Relações Internacionais e do curso de Graduação em Relações Internacionais da Universidade Paulista (UNIP). E-mail: <charlespennaforte@gmail.com>. Recebidoem: 07.04.3014, aceito em: 29.05.2014. 


\section{INTRODUÇÃO}

O projeto chavista de inserção da Venezuela no sistema-mundo contemporâneo enfrenta inúmeros obstáculos, tanto de ordem interna como externa. Devemos reconhecer a grande habilidade política de Hugo Chávez (1954-2013) na consolidação do seu poder desde o final dos anos 1990 até a sua morte em 2013. Por outro lado, deve-se assinalar que a velha elite política venezuelana não teve a habilidade necessária em lidar com o "fenômeno Chávez", optando por desacreditar o processo que estava ocorrendo no país facilitando, de certo modo, a consolidação desse poder.

O golpe arquitetado pelos setores conservadores contra um governo eleito democraticamente em 2002, e a recusa em participar das eleições legislativas de 2005, por "falta de garantias democráticas" (PARUOLO, 2010), favoreceram a supremacia política do Partido Socialista Unido da Venezuela (PSUV), o partido chavista (PARUOLO, 2010). Com a supremacia política, Chávez pôde atuar com tranquilidade no desenvolvimento do projeto bolivariano. No âmbito interno o sucesso deste projeto estava intimamente ligado à manutenção do poder em sua figura pessoal no Palácio de Miraflores. A falta de outras lideranças de projeção nacional configura-se em um problema importante depois de sua morte.

Outro aspecto importante é que, apesar de Caracas atuar frontalmente contra as diretrizes políticas de Washington e do seu discurso anti-imperialista, as exportações de petróleo para o país se mantiveram intactas. Isso aponta para a realidade adversa encontrada pela Venezuela na dependência econômica de seu principal inimigo político e ideológico.

Os EUA são os principais compradores do petróleo cru pesado venezuelano e tem capacidade de refiná-lo (SENHORAS e GAMA NETO, 2009). Outro grande problema para o projeto antissistêmico bolivariano é a baixa industrialização do país. Como atuar de maneira independente dentro do sistema-mundo quando não se possui os mecanismos que possibilitem isso?

Como decorrência de tais aspectos, a Venezuela procurou aumentar a sua influência continental e internacional de maneira mais enfática aliando a ideologia e a construção de parcerias políticas e econômicas tanto com países latino-americanos como de outras partes do mundo. A diversificação dos laços econômicos é um importante componente para o desenvolvimento da atuação antissistêmica.

Durante grande parte dos seus mandatos, Hugo Chávez procurou estabelecer relações diplomáticas e econômicas com países que estivessem no polo oposto às diretrizes da Casa Branca. Para ganhar projeção internacional compatível com o processo político-ideológico que estava desenvolvendo na Venezuela, Chávez procurou difundir sua atuação antissistêmica.

Nas próximas páginas, discutiremos os principais projetos de atuação antissistêmica da Venezuela. Em todos eles, possui lugar central o elemento da integração regional. 


\section{A VENEZUELA E A INTEGRAÇÃO REGIONAL}

A Venezuela é entusiasta e incentivadora de todas as formas de diminuir a dependência econômica externa da América Latina e do avanço do processo de integração regional. O país está presente em todos os organismos regionais que apontem nessa direção e sempre que possível com uma atuação de liderança.

Essa participação em diversos organismos não ocasiona um conflito de interesses para os venezuelanos. Pelo contrário, serve como uma forma de complementariedade do processo de integração da América Latina. A existência dessa variedade de organizações reflete as assimetrias existentes no subcontinente americano.

As iniciativas promovidas por Caracas com a criação da Aliança Bolivariana para as Américas-Tratado de Comércio dos Povos (ALBA-TCP), do Banco da ALBA e da Petrocaribe, por exemplo, demonstram o firme objetivo de diminuição da influência norte-americana na América Latina. Um novo reposicionamento da América Latina no sistema-mundo contemporâneo é um objetivo fundamental da Venezuela bolivariana.

Faremos a seguir uma análise da participação da Venezuela nos organismos regionais.

\subsection{ALIANÇA BOLIVARIANA PARA AS AMÉRICAS-TRATADO DE COMÉRCIO DOS POVOS (ALBA-TCP)}

A ALBA-TCP foi criada em oposição à proposta defendida pelos EUA de implementação da Área de Livre-Comércio das Américas (ALCA) ${ }^{(1)}$ e gerou um importante contraponto ideológico, econômico e político na América Latina a Washington.

A proposta de elaboração da ALBA foi apontada pela primeira vez por Hugo Chávez na III Cumbre de Chefes de Estado e de Governo, na Ilha de Margarita em dezembro de 2001 (ROSA, 2011, p. 91). No evento, Chavéz assinalou a necessidade de superação do modelo do neoliberal por outro baseado na integração latino-americana:

Ese modelo neoliberal no puede ser la base ni el marco para nuestros modelos de integración. No puede ser, es imposible que nosotros pongamos por delante para integrarnos, a la economía. No es la economía la que nos va a integrar y menos nuestras economías llenas de debilidades, de vulnerabilidades. No. Creo que se impone de nuevo lo que pudiéramos llamar la revancha de la política, que la política vuelva a la carga y que tome la vanguardia de los procesos de integración. Y es la idea de Bolívar. (...) Un pacto político es lo que se impone hoy como era lo que se imponía entonces, y una integración integral, a lo bolivariano. El ALCA, por ejemplo, ¿es ese el camino? No.

Queremos un modelo que nos integre de verdad. No un modelo que nos desintegre, que integre a unos a expensas de la desintegración de otros, ese no puede ser el camino, por

(1) A Área de Livre-Comércio das Américas (ALCA) foi uma proposta feita pelos Estados Unidos, durante a Cúpula da América (Miami) em dezembro de 1994, com o objetivo de eliminar as barreiras alfandegárias entre os 34 países americanos, exceto Cuba, formando assim uma área de livre de comércio continental até o final de 2005. Contudo, foram feitas inúmeras críticas aos "reais interesses" dos EUA com o projeto de integração, já que as concessões econômicas que deveriam ser feitas por Washington para facilitar o comércio na região nunca saiam do papel. 
tanto con mucha modestia y humildad proponemos desde Venezuela, a los caribeños y a los latinoamericanos que vayamos pensando de una buena vez en otra alternativa porque esa creemos que no es posible. Y es cuando se nos ha ocurrido lanzar una propuesta, que pudiera llamarse el ALBA, Alternativa Bolivariana para las Américas. Un nuevo concepto de integración que no es nada nuevo, se trata de retraer o de traer nuevamente un sueño que creemos posible, se trata de otro camino, se trata de una búsqueda, porque ciertamente la integración para nosotros es vital: O nos unimos o nos hundimos. Escojamos pues las alternativas. (FRÍAS, 2001.)

Em dezembro de 2004, foi realizada em Havana a I Cumbre da ALBA-TCP. Hugo Chávez e Fidel Castro assinaram uma declaração conjunta de criação da ALBA-TCP sobre os princípios que deveriam nortear a organização:

Afirmamos que el principio cardinal que debe guiar el ALBA es la solidaridad más amplia entre los pueblos de América Latina y el Caribe, que se sustenta con el pensamiento de Bolívar, Martí, Sucre, O’Higgins, San Martín, Hidalgo, Petión, Morazán, Sandino, y tantos otros próceres, sin nacionalismos egoístas que nieguen el objetivo de construir una Patria Grande en la América Latina, según lo soñaron los héroes de nuestras luchas emancipadoras. (FRÍAS e RUZ, 2004.)

Outras Cumbres foram realizadas em 2005, 2006, 2007, 2008 e 2009. Em 2006, sob a presidência de Evo Morales, a Bolívia entra para a ALBA a partir da assinatura do Tratado de Todos os Povos (TCP). A Nicarágua assina a sua inclusão. Dominica e Honduras assinam sua inclusão. Banco da ALBA entra em funcionamento. Em 24 de junho de 2009, o bloco é rebatizado de Aliança Bolivariana para os Povos de Nossa América - Tratado de Comércio dos Povos (ALBA-TCP). Passam a fazer parte Equador, San Vicente, Granadinas, Antígua e Barbuda.

Atualmente, a ALBA-TCP é composta por Venezuela, Cuba, Bolívia, Nicarágua, Dominica, Honduras, Equador, Antígua e Barbuda e São Vicente e Granadinas.

O Tratado de Comércio dos Povos pretende priorizar objetivos sociais, principalmente nas áreas de educação e saúde, respeitando a soberania de cada Estado.

Outro passo importante na direção de maior autonomia econômica ante a necessidade de recursos internacionais foi a criação do Banco da ALBA. A iniciativa do banco surgiu na VI Cúpula da ALBA, na cidade de Caracas, em janeiro de 2008. Com o banco, os países-membros da ALBA-TCP ou outros que venham a participar do projeto poderão ter condições de financiamento para os seus projetos em bases econômicas mais vantajosas.

Prosseguindo com a ideia de independência econômica perante os centros financeiros do sistema-mundo especialmente norte-americano, foi criada uma "moeda" regional para as trocas comerciais entre os países da ALBA-TCP. Na VII Cumbre, realizada em 2009, foi deliberada a criação de uma moeda, o Sistema Unitário de Compensação Regional de Pago (Sucre). O objetivo era diminuir cada vez mais a dependência do dólar nas transações comerciais. 
De início, o Sucre foi pensado para ser uma moeda virtual. Ele serviria para a padronização do intercâmbio comercial e para pagamentos entre os bancos centrais dos países que tiverem aderido ao sistema. É possível notar claramente a influência do Euro como padrão a ser seguido pelos países envolvidos. O valor do Sucre decorre de uma média de valores das moedas dos países que assinaram o Tratado Constitutivo do Sucre (2009). A fase final do Sucre ocorrerá com a emissão física da moeda, sem data estipulada para acontecer.

Em 27 de janeiro de 2010, foram emitidos 152 milhões de "sucres" para distribuição entre os países aderentes e, no dia 3 de fevereiro, foi feita a primeira operação comercial envolvendo a Venezuela e Cuba com o Sucre.

Comparando com o MERCOSUL — que já possui mais de duas décadas de existência - o avanço da ALBA-TCP no quesito de implantação de uma moeda única demonstrou a vontade política da Venezuela em acelerar o processo de integração monetária. Sabemos que as economias da ALBA-TCP possuem pequeno desenvolvimento fato que, quando comparado às economias do Brasil e Argentina, por exemplo, facilitariam a integração monetária no médio e longo prazo, sem contar os aspectos políticos domésticos que influenciam políticas macroeconômicas que dificultariam a criação da moeda única no MERCOSUL.

Contudo, os aspectos mais importantes são o político e o simbólico. Mais especificamente ao colocar a questão da unificação monetária como um objetivo importante dentro da integração econômica da ALBA-TCP, e implementá-lo em um curto espaço de tempo.

\subsection{O MERCADO COMUM DO SUL (MERCOSUL)}

Com a perspectiva de manter-se inserida e participar da vida econômica latino-americana com parceiros de maior importância, como o Brasil e a Argentina, a Venezuela ratificou o protocolo de entrada ao MERCOSUL em julho de 2006.

A parceria com o Brasil, por exemplo, é de grande importância para os venezuelanos. O destaque alcançado por Brasília na última década reforçou a percepção da liderança brasileira no cenário internacional como um interlocutor reconhecido pela comunidade. Seu interesse em participar do MERCOSUL é perfeitamente natural para o projeto antissistêmico e bolivariano.

Em dezembro de 2009, o Senado brasileiro aprovou a entrada da Venezuela no Mercosul. A Venezuela era então um Estado associado em processo de adesão. A última fase da configuração do país como pleno foi a votação do Congresso paraguaio, o que só ocorreu em 2012.

A adesão ocorreu depois da saída do país da Comunidade Andina de Nações em 2006. O que precipitou tal decisão foi a assinatura de Tratados de Livre-Comércio (TLC) com os EUA por parte da Colômbia e Peru. Segundo os venezuelanos:

(...) os TLCs promoviam os princípios do liberalismo norte-americano, cujo objetivo era unificar os mercados do mundo para obter mais expansão. Tais objetivos fugiam totalmente da política de integração latino-americana que promove o governo venezuelano baseada 
em quatro princípios: cooperação, solidariedade, complementação econômica e respeito à soberania das nações. (MENDEZ, 2008, p. 27-28.)

O governo venezuelano foi veemente em suas críticas à aproximação de peruanos e colombianos da órbita de influência dos EUA. Tais tratados, portanto, fugiriam totalmente da perspectiva antissistêmica defendida pela Venezuela. Se o objetivo foi contrapor a influência de Washington, não havia sentido a manutenção de uma organização de características opostas.

\subsection{COMUNIDADE DOS ESTADOS LATINO-AMERICANOS E CARIBENHOS (CELAC)}

Em julho de 2008, o ex-presidente Luiz Inácio Lula da Silva (2003-2010) convocou a I Cúpula de Mandatários da América Latina e Caribe, com o objetivo de debater e estabelecer objetivos para o desenvolvimento regional e a integração. Posteriormente, em fevereiro de 2010, em Playa del Carmen (México) conjuntamente com a XXI Cúpula do Grupo do Rio e a II Cúpula da América Latina e do Caribe sobre Integração e Desenvolvimento (CALC), efetivou-se com a criação da Comunidade dos Estados Latino-Americanos e Caribenhos (CELAC). Na Declaração de Cancún (CELAC, 2010) foi decidido:

1. Intensificar el diálogo político entre nuestros Estados y traducir, a través de la concertación política, nuestros principios y valores en consensos. La región requiere de una instancia de concertación política fortalecida que afiance su posición internacional y se traduzca en acciones rápidas y eficaces que promuevan los intereses latinoamericanos y caribeños frente a los nuevos temas de la agenda internacional.

2. Intensificar para ello, la concertación de posiciones regionales de cara a reuniones y conferencias de alcance global y adoptar un perfil más dinámico a favor de la concertación política y del trabajo de interlocución con otras regiones y países en la convicción de que ese diálogo contribuye a proyectar a la región y aumentar su influencia en el escenario internacional globalizado e interdependiente.

3. Reafirmar que la preservación de la democracia y de los valores democráticos, la vigencia de las instituciones y el Estado de Derecho, el compromiso con el respeto y la plena vigencia de todos los derechos humanos para todos, son objetivos esenciales de nuestros países.

4. Impulsar una agenda integrada, con base en el patrimonio del Grupo de Río y los acuerdos de la CALC, así como de los mecanismos y agrupaciones de integración, cooperación y concertación ya existentes, que constituyen todos, de conjunto, un valioso activo regional que se sustenta en los principios y valores compartidos, con el propósito de dar continuidad a nuestros mandatos mediante un programa de trabajo que promueva vínculos efectivos, la cooperación, el crecimiento económico con equidad, justicia social, y en armonía con la naturaleza para un desarrollo sostenible y la integración de América Latina y el Caribe en su conjunto.

Dentro dessa perspectiva, a CELAC oferece outra arena para aumentar a independência política e econômica dos países latino-americanos em relação a Washington, principalmente dos países que fazem parte da ALBA-TCP. 
É possível constatar que a participação enfática venezuelana nos fóruns latino-americanos se desenvolve na perspectiva de criação de uma proposta antagônica à ideia de integração defendida por Washington com a Área de Livre-Comércio das Américas (ALCA) desde 1994.

No Quadro 1, podemos observar como o processo de interação vem ocorrendo no continente. A partir de dos anos 1990, o MERCOSUL e o novo contexto político da América Latina acelerou a perspectiva "integracionista", apesar das assimetrias existentes.

TABELA 01

EVOLUÇÃO DA INTEGRAÇÃO SUL-AMERICANA

\begin{tabular}{lllll}
\hline Assinado em & 1969 & 1991 & 2004 & 2008 \\
vigor & 1969 & 1991 & 2004 & 2011 \\
Documento & $\begin{array}{l}\text { Acordo de } \\
\text { Cartagena }\end{array}$ & $\begin{array}{l}\text { Tratado } \\
\text { de Assun- } \\
\text { ção }\end{array}$ & $\begin{array}{l}\text { Declaração } \\
\text { de Cuzco }\end{array}$ & $\begin{array}{l}\text { Tratado Constitutivo } \\
\end{array}$ \\
& & &
\end{tabular}

União de Nações Sul-Americanas (UNASUL)

Pacto Andino (Comunidade Andina de Nações)

Mercosul (Mercado Comum do Sul)

Elaborado pelo autor

O processo de integração, pelo menos político, se acentua cada vez mais sem a presença de Washington e fortalece a ideia bolivariana defendida pelo ex-presidente Hugo Chávez durante os seus governos: uma unificação política e econômica da região. Nesta direção, houve a assinatura do Tratado Constitutivo da UNASUL em maio de 2008.

\subsection{UNIÃO DAS NAÇÕES SUL-AMERICANAS (UNASUL)}

Denominada inicialmente de Comunidade Sul-Americana de Nações, configurou-se a partir da integração de duas uniões aduaneiras: MERCOSUL e a Comunidade Andina de Nações (CAN). A ideia era manter o processo de integração do continente em processo dinâmico permanente. Contudo, a proposta foi vista com ceticismo em virtude das disparidades políticas e econômicas existentes. Do ponto de vista de consolidação do projeto em médio e longo prazos, acreditamos que ele terá sucesso por demonstrar a importância da integração Latino-americana em busca de metas comuns ante a um sistema-mundo em crise.

A UNASUL possui sete conselhos que envolvem as seguintes áreas: Desenvolvimento Social, Combate ao Tráfico de Drogas, Educação, Cultura, Ciência, Tecnologia e Inovação; Energia, Infraestrutura e Planejamento, Economia e Finanças. São tais conselhos que terão a função de colocar em prática medidas que promovam o desenvolvimento do subcontinente nestas áreas. O Mapa 01 apresenta a área abrangida.

Um aspecto importante na proposta da UNASUL é que ela facilita a discussão de integração física do continente além do aspecto econômico. "Diminuir as distâncias" é um fator fundamental 
na integração sul-americana. Com a integração política, econômica e de infraestrutura, a região passa a contar com maior força para enfrentar os desafios impostos pelo processo de globalização, ao mesmo tempo em que diminui a sua dependência dos mercados internacionais.

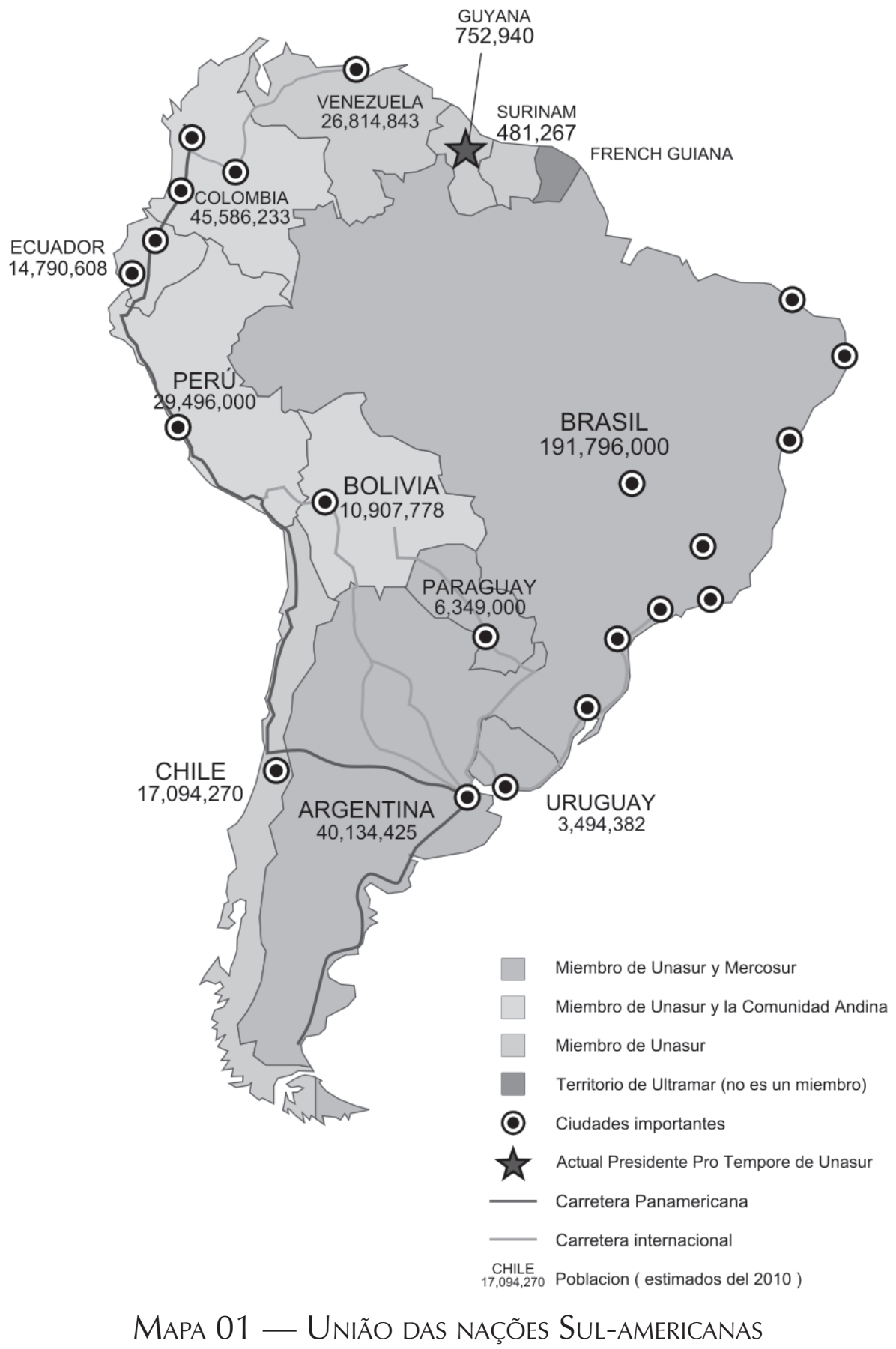

Elaborado por Camilo Sanchez. Disponível em: <http://commons.wikimedia.org/wiki/File:Mapa_de_unasur.svg>. Acessado em: 29.11.2011. 
Neste aspecto, a Integração da Infraestrutura Regional Sul Americana (IIRSA), criada em 2000 por uma proposta do governo brasileiro e que contou com o apoio dos doze países da região, criou o ambiente favorável para a discussão sobre a importância da integração da infraestrutura regional latino-americana.

Com países com níveis de desenvolvimento econômico díspares, é fundamental que a infraestrutura seja uma das prioridades para a real integração da região ao facilitar o comércio entre as nações, bem como o próprio desenvolvimento social. O projeto conta com o apoio financeiro do Banco Interamericano de Desenvolvimento (BID), da Corporación Andina de Fomento (CAF), do Fondo Financiero para el Desarrollo de los Países de la Cuenca del Plata (FONPLATA) e do Banco Nacional de Desenvolvimento Econômico e Social (BNDES).

Para os países que possuem economias de menor porte, a iniciativa para a IIRSA surge como uma grande oportunidade para melhorar a sua infraestrutura, fato que dificilmente ocorreria pela falta de recursos desses países. Trata-se de um grande avanço para a região.

\section{DESAFIOS À ATUAÇÃO ANTISSISTÊMICA}

Depois do colapso do socialismo real no início dos anos 1990, a economia-mundo capitalista tornou-se hegemônica e incorporou quase todo o planeta (WALLENSTEIN, 2000, 2001, 2003, 2004, 2011). A própria China (que se denomina "comunista") inseriu-se nela no início dos anos 1980 e assumiu padrões civilizatórios dentro da lógica de consumo. Não discutimos aqui a questão do sistema político do país ser baseado no partido único e que contraria os preceitos liberais defendidos no Ocidente.

A atuação fora dessa lógica econômica e social é extremamente complicada em função do capitalismo ser um sistema social histórico e um processo civilizatório ${ }^{(2)}$. Mais do que o consumo como base econômica, o sistema-mundo capitalista organiza também o nível cultural por meio da ideologia. Trata-se de um estágio de desenvolvimento no qual as economias estão cada vez mais conectadas e o padrão cultural é ditado a partir dos países centrais hegemônicos mediante o controle de capital, dos meios de comunicação tradicionais e digitais.

Deste modo, a tentativa da Venezuela em atuar de maneira antissistêmica envolve uma série de problemas. Para o país, a baixa industrialização e a dependência do petróleo representam os principais obstáculos para uma atuação antissistêmica. A industrialização venezuelana nos atuais patamares coloca o país em condições econômicas vulneráveis pois cria a necessidade de importações de bens de produção e de consumo de maneira permanente. Tal fato impede uma real independência dentro do atual sistema-mundo.

Enquanto esteve à frente do comando da Venezuela, Hugo Chávez não conseguiu lograr sucesso na criação de condições econômicas que superassem o paradigma do atraso industrial da Venezuela. A dependência do petróleo é o mais emblemático problema do país.

(2) Wallerstein em seu livro Capitalismo Histórico e Civilização Capitalista (2001) analisa de maneira detalhada a configuração do capitalismo enquanto fenômeno que transcende o aspecto econômico. Segundo ele: "O Capitalismo é, em primeiro lugar e principalmente, um sistema social histórico". (...) "Algo distingue o sistema social que estamos chamando de capitalismo histórico: nele, o capital passou a ser usado (investido) de maneira especial, tendo como objetivo, ou intenção primordial, a auto-expansão. Nesse sistema, o que acumulou no passado só é 'capital' na medida em que seja usado para acumular mais da mesma coisa. Trata-se de um processo complexo, até sinuoso (...). Usamos a expressão 'capitalistas' para nomear essa meta persistente e autocentrada do detentor do capital (a acumulação de mais capital) e as relações que ele tem de estabelecer com outras pessoas para alcançá-lo". (WALLERSTEIN, 2001, p. 13-14) 
Mais preocupante para o desempenho da Venezuela como ator antissistêmico no sistema-mundo capitalista é ter uma vinculação econômica de grande importância com o seu inimigo declarado: os EUA. As exportações petrolíferas para os Estados Unidos representam uma grande importância para a economia da Venezuela. Sabemos também que o rompimento com tal modelo não pode ser feito em pouco tempo. Requer algumas décadas para cindir com tal processo histórico. Contudo, é imperativa a necessidade de uma mudança deste paradigma econômico quando se pensa em uma atuação antissistêmica.

Durante os seus governos, Hugo Chávez procurou a diversificação dos seus parceiros econômicos. A dinamização da ALBA-TCP, UNASUL e as "petros" no subcontinente estão dentro deste projeto. A integração regional latino-americana vai ao encontro desta perspectiva, pois diminui a dependência econômica dos EUA. Entretanto, o petróleo segue com o principal produto de exportação do país para os EUA.

O sistema-mundo capitalista impede que os países consigam uma autonomia comercial e tecnológica perante as outras nações. Isso é utópico do ponto de vista prático. A maior nação do sistema-mundo não possui esta autonomia. A relação com China, o déficit comercial com os japoneses, e a dependência do petróleo do Oriente Médio e até mesmo da Venezuela, demonstram a impossibilidade de uma autonomia total dos EUA.

A diversificação dos parceiros comerciais é uma boa saída para a economia venezuelana, contudo, pode criar outras dependências no longo prazo. A dependência estrutural é o principal problema para qualquer país. Como exemplo, podemos citar o aumento da influência chinesa no continente.

A participação chinesa na América Latina e na Venezuela aumentou consideravelmente. A duplicação do Fundo Comum Chinês-Venezuelano (FCCV), em 2009, foi importante para o país ao garantir mais recursos em caixa para eventuais problemas decorrentes da crise sistêmica de 2008. Todavia, isso aponta para a possibilidade do deslocamento da dependência para os chineses.

Por outro lado, na arena político-ideológica, a Venezuela conseguiu se sair bem em nossa concepção. Desde que Chávez iniciou o seu projeto de uma inserção antissistêmica no sistema-mundo atual, o país conseguiu grande destaque. O número de países que passaram a aceitar a sua liderança no processo político-econômico regional aumentou consideravelmente. O sucesso da ALBA-TCP, a despeito das críticas feitas ao bloco, é um dos exemplos da atuação antissistêmica venezuelana.

A Venezuela participa de todos os fóruns regionais com propostas sempre voltadas para a integração, diminuição da dependência financeira internacional e da denúncia do imperialismo norte-americano no continente. Como já salientamos, a América Latina perdeu importância gradativa nas últimas décadas e parece que uma volta à hegemonia de Washington está cada vez mais distante no médio prazo.

\section{CONCLUSÃO}

A Venezuela seria realmente um player internacional? Em nossa concepção, a Venezuela, dentro de suas possibilidades econômicas, políticas e militares, conseguiu um grande destaque como player internacional limitado sob o projeto antissistêmico de Hugo Chávez. Logicamente, devemos situar este desempenho dentro de parâmetros 
compatíveis à Venezuela e, com o desaparecimento do carismático líder venezuelano, a tendência é de uma diminuição desta atuação.

A utilização do chamado soft power pela utilização do "petróleo com fins humanitários" é outra forma de a Venezuela conseguir uma "boa imagem” na América Latina. A venda de petróleo subsidiado aos cubanos e a preços menores para outros países da ALBA-TCP colaboram para uma boa imagem da Venezuela. Por outro lado, as elites conservadores promovem por intermédio da mídia justamente o contrário entre as classes médias latino-americanas: denunciam a Venezuela como tendo um governo ditatorial apesar das eleições serem monitoradas pelos organismos internacionais.

A sua política externa pró-ativa e independente das pressões vindas de Washington pode ser visualizada pelos contatos feitos com países que figuram ou figuraram como "inimigos" de Washington. Um caso destacado foram os contatos com Teerã. Quando toda a comunidade internacional fazia uma forte pressão contra o Irã, a Venezuela em nenhum momento pensou em seguir as orientações emanadas principalmente de Washington e manteve inúmeros contatos de alto nível entre os dois países.

A posição venezuelana na construção de um mundo multipolar se caracteriza de maneira mais enfática do que a vista em países como o Brasil, a Rússia ou a China. O que denominamos como "enfático" é que o Palácio de Miraflores nomeia o "inimigo" claramente como sendo os EUA e denuncia seus "atos" sem se importar com aspectos diplomáticos de suas afirmativas.

A despeito das contradições existentes, a Venezuela vem conseguindo desenvolver o seu papel antissistêmico dentro de um processo dialético, ou seja, que envolve inúmeros avanços e retrocessos. Os resultados só poderão ser avaliados com a superação dessas dicotomias. Agora, sob o comando de Nicolás Maduro.

\section{BIBLIOGRAFIA}

ALBA. Tratado Constitutivo del Sistema Unitario de Compensación Regional de Pagos — SUCRE. Cochabamba, 16 de octubre de 2009.

CELAC. Declaración de Cancún. Cancún, 23 de febrero de 2010. Disponível em: <http://www.celac. gob.ve/index.php?option=com_content $\&$ view=article $\&$ id $=27 \&$ Itemid=3\&lang=es $>$ Acesso em: 02.06.2012.

FRÍAS, Hugo Rafael Chávez. “¿Qué son los TCP Tratados de Comercio de los Pueblos?” Margarita: 11 de dezembro de 2001. Discurso proferido na III Cumbre de Jefes de Estado y de Gobierno de la Asociación de Estados del Caribe. Disponível em: <http://www.alianzabolivariana.org/modules.ph p? name $=$ Content $\&$ pa $=$ showpage $\&$ pid=2080 $>$ Acesso em: 15.11.2011.

FRÍAS, Hugo Rafael Chávez; RUZ, Fidel Castro. Declaración conjunta. Havana, 15 de diciembre de 2004.

MENDEZ, Carlos Romero. Las relaciones de seguridad entre Venezuela y Estados Unidos: la dimensión global. In: Venezuela en el contexto de la seguridad regional. Caracas: Instituto Latinoamericano de Investigaciones Sociales, 2007.

PARUOLO, Ana Luiza Meirelles et al. As transformações na Democracia Venezuelana de 1999 a 2010 e as eleições legislativas de setembro de 2010. Rio de Janeiro, Boletim Tempo Presente, UFRJ. 
Disponível em: <http://www.getempo.org/revistaget.asp?id_edicao=19\&id_materia=72> Acesso em: 02.06.2012.

ROSA, la Francisco Ullán. La Alianza Bolivariana para las Américas-Tratado de Comercio de los Pueblos (ALABA-TCP): análisis de un proyecto de integración regional latino-americana con una fuerte dimensión altermundista. Paper, Alicante, España. Universitas: Relações Internacionais, Brasília, v. 09, n. 02, p. 91-137, jul./dez. 2011.

SENHORAS, Elói Martins; GAMA NETO, Ricardo Borges. Petróleo como arma de poder: Uma contextualização da petrodiplomacia venezuelana nas relações internacionais. Boletim Meridiano 47, v. 10, n. 105, 2009. Disponível em: <http://seer.bce.unb.br/index.php/MED/article/view/722/439> Acesso em: 30.11.2011.

WALLENSTEIN, Immanuel. Geopolitics, class politics, and the current world disorder. Rio de Janeiro: Seminar International REGGEN, 2003. O declínio do poder Americano. Rio de Janeiro: Contraponto, 2004. . Capitalismo histórico e civilização capitalista. Rio de Janeiro: Contraponto, 2001. Globalization or the Age of Transition? A Long-Term View of the Trajectory of the World System. International Sociology, Madri, v. 15, n. 2, p. 251-267, June 2000. Disponível em: <http:// www.iwallerstein.com/wp-content/uploads/docs/TRAJWS1.PDF> Acesso em: 03.12.2011. 